\title{
Declining temperature and increasing moisture sensitivity of shrub growth in the Low-Arctic erect dwarf-shrub tundra of western Greenland
}

\author{
Stef Weijers ${ }^{1}$ \\ ${ }^{1}$ Rheinische Friedrich-Wilhelms-Universitat Bonn
}

February 4, 2022

\begin{abstract}
1. Evergreen dwarf shrubs respond swiftly to warming in the cool and dry High Arctic, but their response in the warmer Low Arctic, where they are expected to be outcompeted by taller species under future warming, remains to be clarified. 2 . Here, 12,528 annual growth increments, covering 122 years (1893-2014), were measured of 764 branches from 25 individuals of the evergreen dwarf shrub Cassiope tetragona from a Low-Arctic erect dwarf-shrub tundra site in western Greenland. In addition, branch initiation and mortality frequency time-series were developed. The influence of seasonal climate and correspondence with fluctuations in regional normalized difference vegetation index (NDVI), a satellite-proxy for vegetation productivity, were studied. 3. Winter temperatures were an important co-driver, summer temperatures the main driver of growth. During past and recent warm episodes, shrub growth diverged from summer temperatures. In recent decades, early summer precipitation has become the main growth-limiting factor for some individuals, likely through micro-topography-determined soil moisture availability, and more than half of the shrubs studied became irresponsive to summer temperatures. There was correspondence between climatic drivers, C. tetragona growth and branch initiation frequency, and satellite-observed vegetation productivity, suggesting the area's shrub-dominated tundra vegetation is limited by similar climatic factors. Winter warming events were likely the predominant cause of branch mortality, while branching increased after years with poor growth and cooler-than-average summers. 4. Synthesis These findings show that the erect dwarf-shrub tundra in the Low Arctic has and will likely become less temperature- and increasingly moisture-limited and that winter warming supports shrub growth, but increased extreme winter warming event-frequency may increase branch mortality and vegetation damage. Such counter-acting mechanisms could offer an explanation for the vegetation stability observed over large parts of the Arctic.
\end{abstract}

Declining temperature and increasing moisture sensitivity of shrub growth in the Low-Arctic erect dwarf-shrub tundra of western Greenland

Stef Weijers

Department of Geography, University of Bonn, Meckenheimer Allee 166, D-53115 Bonn, Germany

Phone: +49228732093

E-mail: weijers@uni-bonn.de

OrcID: 0000-0003-3386-5417

\section{Abstract}

1. Evergreen dwarf shrubs respond swiftly to warming in the cool and dry High Arctic, but their response in the warmer Low Arctic, where they are expected to be outcompeted by taller species under future warming, remains to be clarified. 
2. Here, 12,528 annual growth increments, covering 122 years (1893-2014), were measured of 764 branches from 25 individuals of the evergreen dwarf shrub Cassiope tetragona from a Low-Arctic erect dwarfshrub tundra site in western Greenland. In addition, branch initiation and mortality frequency timeseries were developed. The influence of seasonal climate and correspondence with fluctuations in regional normalized difference vegetation index (NDVI), a satellite-proxy for vegetation productivity, were studied.

3. Winter temperatures were an important co-driver, summer temperatures the main driver of growth. During past and recent warm episodes, shrub growth diverged from summer temperatures. In recent decades, early summer precipitation has become the main growth-limiting factor for some individuals, likely through micro-topography-determined soil moisture availability, and more than half of the shrubs studied became irresponsive to summer temperatures. There was correspondence between climatic drivers, C. tetragona growth and branch initiation frequency, and satellite-observed vegetation productivity, suggesting the area's shrub-dominated tundra vegetation is limited by similar climatic factors. Winter warming events were likely the predominant cause of branch mortality, while branching increased after years with poor growth and cooler-than-average summers.

4. Synthesis These findings show that the erect dwarf-shrub tundra in the Low Arctic has and will likely become less temperature- and increasingly moisture-limited and that winter warming supports shrub growth, but increased extreme winter warming event-frequency may increase branch mortality and vegetation damage. Such counter-acting mechanisms could offer an explanation for the vegetation stability observed over large parts of the Arctic.

\section{Keywords}

branching, branch mortality, browning, greening, NDVI, shrub expansion, soil moisture, winter warming events

\section{Introduction}

Arctic and alpine areas are warming at faster rates than other areas, partly because of decreased albedo after advanced snowmelt, and feedback mechanisms related to the decline in Arctic sea-ice extent. The Arctic tundra biome is divided into five bioclimatic subzones, which are defined by summer temperatures and dominant plant growth forms in each zone. The vertical tundra vegetation structure varies from a discontinuous layer of very short plants in the coldest zone to multi-layered, complex canopies in the warmest zone. As a consequence of the rapid warming, these vegetation zones are expected to shift northward and into higher elevations. Plant height has already increased over the past thirty years throughout the tundra biome, largely caused by species turnover due to immigration of taller species from warmer areas . This is at least partially related to the increase in productivity and abundance of deciduous shrub species . Such an increase in canopy height, because of increased abundance of tall shrub species may lead to an increase in competition for light and a decrease in dwarf shrub abundance, particularly in the Low- and Sub-Arctic tundra. However, the potential of deciduous shrubs to increase with summer warming, likely depends on soil moisture availability. Deciduous shrub growth has increased rapidly with recent warming in warmer wetter areas, while it has declined in dry tundra areas in recent decades, possibly in relation to diminishing sea-ice extent . In the cooler and drier High Arctic, evergreen dwarf shrub growth has increased rapidly with recent warming and leaf size and plant height of evergreen dwarf shrubs increases to long-term experimental warming . However, it remains unknown whether evergreen dwarf shrubs, which are generally better adapted to drier conditions and are found on well-drained, relatively dry soils, can respond with increased growth to the amplified warming in the already warm Low Arctic.

The satellite-based normalized difference vegetation index (NDVI) is generally regarded as a proxy for biomass and productivity of terrestrial vegetation. NDVI analyses have revealed long-term greening trends over large parts of the tundra biome in the northern hemisphere in recent decades . Nonetheless, a significant percentage of Arctic ecosystems appears to be stable and the mechanisms behind this stability are poorly understood. Interannual variation in NDVI in the Siberian Arctic and Arctic-alpine northwest North America have been related to interannual variation in shrub growth and summer temperatures. This suggests 
a possible link between summer warming-induced Arctic greening and shrub growth. Although many tundra areas have experienced greening over the past decades, other regions have experienced browning events in recent times. Such browning events have been linked to the occurrence of extreme warm spells in winter, which result in snowmelt, often accompanied by rain-on-snow events . These may result in the encasement of plants in ground-ice or leave plants exposed to subsequent periods of severe frost without insulation by a sufficiently deep snow layer. Extreme winter warming and rain-on-snow events, the frequency of which is likely to increase in the future, can damage vegetation and lower its productivity in the subsequent summer . Single events have been linked to branch mortality of several shrub species, including Cassiope tetragona . Still, shrub branch-mortality and branch-initiation frequency time-series and possible links with climate and NDVI have not been studied thus far.

Here, the climate-growth relationships in the evergreen dwarf shrub Cassiope tetragona are studied at a LowArctic site in western Greenland. The species is found throughout the Arctic, but is most prevalent in the High Arctic . The following research questions were addressed:

1. What are the main seasonal climate drivers of C. tetragonashrub growth at the site and individual shrub level and are these stable over time?

2. Are there differences in individual shrub growth responses to climate and are these related to microtopographic positions?

3. Is annual variation in branch initiation and mortality frequency related to variation in seasonal climate variables?

4. Are area-wide, satellite-observed vegetation productivity, C. tetragona growth, branch initiation and mortality frequencies, and seasonal climate factors inter-related?

\section{Materials and Methods}

\section{Site description}

On 6 August 2014, 25 Cassiope tetragona shrubs were sampled at a mesic tundra site $\left(69.26{ }^{\circ} \mathrm{N}, 53.48{ }^{\circ} \mathrm{W}\right.$, $45 \mathrm{~m}$ above sea level [m a.s.l.]; Fig. 1a-c) located in the Blæsedalen valley about $2 \mathrm{~km}$ northeast of Arctic Station near Qeqertarsuaq on the southern tip of Disko Island, western Greenland. The area's soils consist of basaltic rock fragments, covered by a $5-10 \mathrm{~cm}$ organic horizon, while active layer depths can reach $1.5 \mathrm{~m}$ . The geology of the area is characterized by a low bench of gneiss bedrock, Tertiary breccia and plateau lava. Shrub samples were collected in an area of approx. $60 \mathrm{~m} \times 100 \mathrm{~m}$. A minimum of 1-2 $\mathrm{m}$ distance was kept between sampling spots to avoid repeated sampling of the same shrub individual. It was attempted to sample complete (excl. roots) shrub individuals by following shrub branches until reaching the root-shoot boundary.

The vegetation at the site can be described as erect dwarf-shrub tundra, which covers 9.7 (13.7) percent, i.e. $689 \times 10^{3} \mathrm{~km}^{2}$, of the (non-glaciated) Arctic . It is dominated by the deciduous shrub species Betula nana , Salix glauca, and Vaccinium uliginosum and the evergreen shrub species Cassiope tetragona, Empetrum nigrum ssp.hermaphroditum, and less frequently, Rhododendron tomentosum . The climate at the site is LowArctic with a mean annual air temperature of $-2.3{ }^{\circ} \mathrm{C}$ measured over the period 1994-2013 at ClimateBasis Disko , $3 \mathrm{~km}$ southwest of the site, and an interpolated annual precipitation sum of $330 \mathrm{~mm}$ over the same period (Fig. 1d). February was the month with the lowest mean air temperature $\left(-13.0^{\circ} \mathrm{C}\right)$ and March the month with the lowest mean minimum air temperature $\left(-16.4{ }^{\circ} \mathrm{C}\right)$. July is the warmest month with a mean air temperature of $8.5{ }^{\circ} \mathrm{C}$ and a mean maximum of $11.4{ }^{\circ} \mathrm{C}$. Mean monthly air temperatures remain below zero from November through April, hence most precipitation falls as snow. Frosts are likely to occur as late as June and as early as September (Fig. 1d). September is the wettest month with a mean precipitation sum of $39.6 \mathrm{~mm}$ and February the driest $(16.1 \mathrm{~mm})$.

The site is located on a gentle south-southeast-facing slope (Fig. 1e) at which C. tetragona is the dominant species (Fig. 1f). Further west near Ilulissat on mainland Greenland, the species is only found on north-facing slopes, while further south in the Disko Bay area, near Aasiaat, the species is absent at low elevations. 

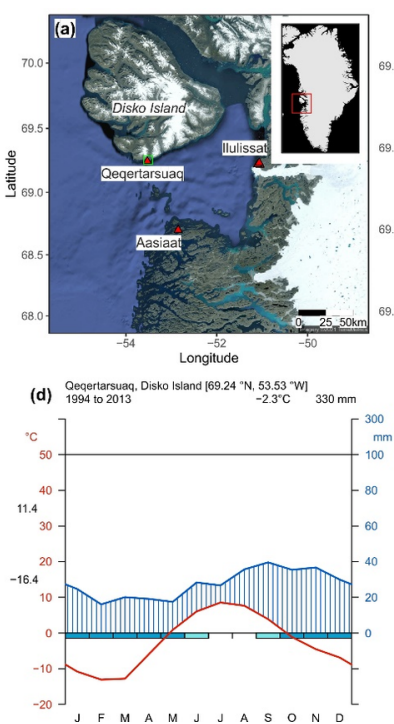

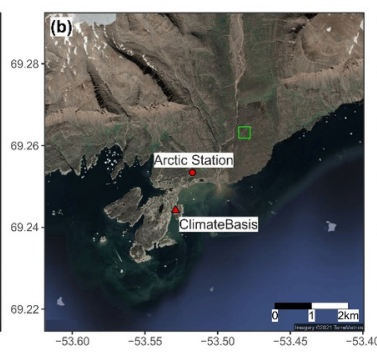

(e)

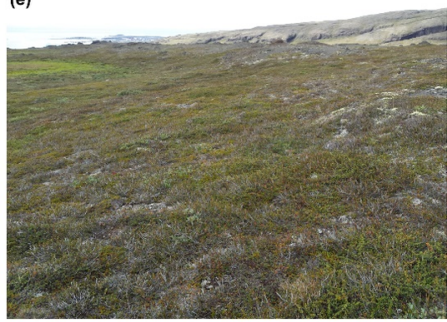

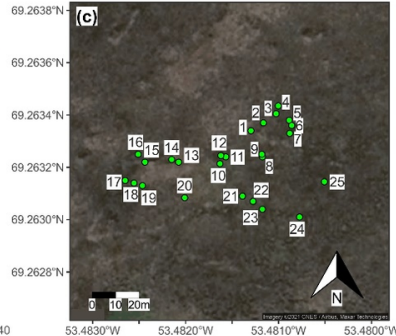

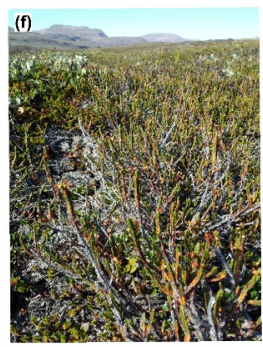

Figure 1 Location of the research site near Qeqertarsuaq on Disko Island (green square); weather station locations are indicated with red triangles (a). The inset map shows the location of the Disko Bay area (red square) within Greenland. Location of the research site (green square) northeast of Arctic Station (b). Local weather is recorded at ClimateBasis Disko, approx. $3 \mathrm{~km}$ southwest of the site. Individual shrub sampling spots (c). Climate diagram showing monthly mean air temperatures (red) and precipitation sums (blue) at Qeqertarsuaq for the period 1994-2013 (d). Values to the left of the temperature axis indicate the mean minimum temperature of the coldest month (February) and the mean maximum temperature of the warmest month (July). Photo of the research site taken from sample 4 in southwestern direction (e). Vegetation at sample spot 24 in north-western direction dominated by Cassiope tetragona shrubs (f).

\section{Species}

Cassiope tetragona (L.) D. Don., common name Arctic Bell Heather, is an evergreen dwarf shrub of the Ericaceae family. The species has a hemi-prostrate growth form and reaches heights of up to $10-15 \mathrm{~cm}$ at the research site, but can grow up to $30 \mathrm{~cm}$ tall when supported by, for example, rocks. It is the dominant species in prostrate/ hemi-prostrate dwarf-shrub tundra, but less so in the erect dwarf-shrub tundra as found at the research site, and has a circumarctic distribution. It occurs in the northernmost polar desert at 83 ${ }^{\circ} \mathrm{N}$ in northern Greenland, where it is the most common heath-forming species . In western Greenland it is found as far south as $63.35^{\circ} \mathrm{N}$, but towards the south only at alpine sites or on north-facing slopes . The species' leaves are attached to its stems in opposite pairs, which alternate in $90^{\circ}$ angles resulting in four rows of leaves (hence tetragona). Leaf lengths rapidly increase at the beginning of the growing season and decrease thereafter, resulting in a wave-like pattern with each wave representing a single growing season . The discovery of so-called wintermarksepta, i.e. dark bands coinciding with lows in leaf lengths visible in lateral cross-sections of C. tetragona branches, has enabled the construction of $>$ century-long growth chronologies . WMS consist of green and with increasing age, brown lignified meristem cells (see Fig. S1).

\section{Shrub growth chronologies}

Annual shoot length growth was measured as distances between WMS for multiple branches of each of the 25 sampled shrubs. This was done for a total 764 branches, 10-65 per shrub. Shoot length growth series of individual branches were cross-dated using the sampling year of shoots with complete and green tips, by plotting and visually comparing similarities in growth patterns between branch series of shrub individuals, and the dates of branching. Older branch series, without any overlap with other series from the same shrub were cross-dated with dated branch series from other shrubs. This mainly concerned some series dating prior to the 1960s (cf. Fig. S2; ). 
Individual branch series of $C$. tetragona generally exhibit growth trends with increasing growth rates during the initial years of growth, approx. during the first ten years in this study. Shoot length growth rates stabilize thereafter, before they start to decline when reaching ages of approx. 50 years. This may result in an overall positive trend in the mean site chronology (Fig. 2) and mean shrub chronologies (Fig. S2). Three different standardization or detrending methods were compared for this study (Table S1, Fig. S3) to remove such growth trends: 1) standardization with a horizontal line through the mean ,2) Regional Curve Standardization, and 3) signal-free multiple RCS-standardization. With the first method, each individual branch series was divided by the related branch mean. In RCS-detrending age-related growth trends are in principle removed, while lower-frequency climatic trends are retained, with an age-related growth curve. In SF-MRCS detrending, multiple RCS curves are calculated for different groups to prevent potential bias resulting from differing growth rates of slow and fast growing individuals . Here, RCS-curves were calculated for 11 groups (each with $\mathrm{n}>50$ ) of branch series ranging from the fastest growing shortest series, to the slowest growing longest series. SF-MRCS detrending was executed in CRUST . RCS detrending and detrending with a horizontal line was performed in $\mathrm{R}$ version 4.0.3 with the 'dplR' package .

All methods resulted in a lowered first-order autocorrelation (Table S1). RCS-detrending retained both shortterm trends and the overall positive trend in site-level mean shoot length growth. In contrast, SF-MRCS detrending resulted in the removal of most trends. Detrending with a horizontal line through the mean had an intermediate effect (Figs 2 and S3). Both RCS- and SF-MRCS detrending reduced the mean correlation between individual branch series (rbar), signal-to-noise ratio, and expressed population signal (EPS; Table S1), and these methods may thus have removed some of the common climatic signal present within the series. Therefore, the series standardized with a horizontal line were used in subsequent analyses.
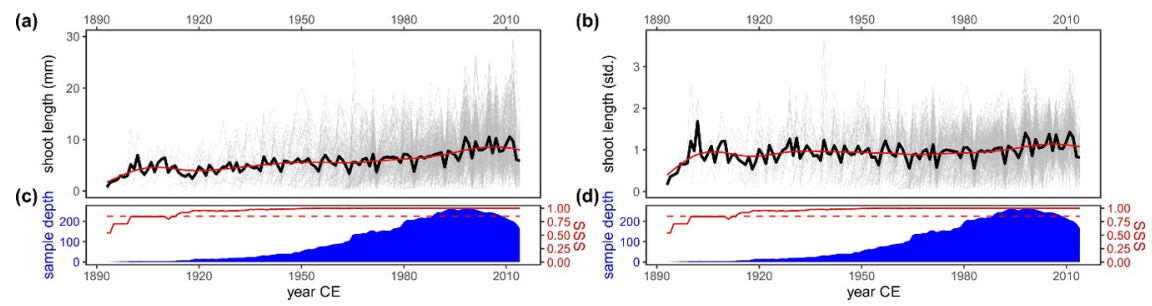

Figure 2 Raw (a) and standardized (b) shoot length growth series (grey lines) together with the site mean (black lines). The red lines through the site means are 30-year cubic smoothing splines with a 50 percent frequency cut-off, which indicate the longer-term trends in the mean site chronologies. The individual branch series in (b) were standardized with a horizontal line through the mean. Sample depth (blue area) and Subsample Signal Strength (SSS; ; red lines) for the raw (c) and standardized (d) site chronology.

\section{Climate data}

Hourly air temperatures measured at $2 \mathrm{~m}$ above ground approx. $3 \mathrm{~km}$ southwest of the research site at ClimateBasis Disko $\left(69.24^{\circ} \mathrm{N}, 53.53^{\circ} \mathrm{W}, 1 \mathrm{~m}\right.$ a.s.l.; Fig. 1b) covering the period 23.09.1993 - 31.12.2019 were downloaded from the GEM database (https://data.g-e-m.dk accessed on 9.3.2021; ). Daily mean temperatures were calculated based on these hourly measurements. Days with fewer than 16 hourly measurements were not further processed. Mean monthly temperatures were calculated based on the daily means for months with at least 20 daily means. This resulted in a mean monthly temperature series from October 1993 to December 2019, with gaps in 1993 (December), 1995 (May-July), 1997 (January, September - December) and 1998 (January). These gaps were filled and the monthly temperature record was extended back to 1880 with temperatures from the homogenized monthly temperature dataset from Ilulissat (; https://crudata.uea.ac.uk/cru/data/greenland/ accessed on 19.03.2021). Monthly mean temperatures from this dataset were transferred using linear regression between this dataset and the ClimateBasis monthly means to match the level of the latter. These records are strongly correlated for each month (0.79[?]r[?]0.99, $\mathrm{p}<0.0001$ ), with on average slightly lower temperatures recorded in Ilulissat. 
Monthly precipitation sums (1901-2019) were extracted from the monthly gridded dataset CRU TS4.04 for the grid 69-69.5 degN, 53.5-53 degW (https://crudata.uea.ac.uk accessed on 14.5.2021; ). This gridded dataset was extended through regression with monthly precipitation sums calculated from daily data measured at Ilulissat (1880-1991; $69.22 \mathrm{degN}, 51.1 \mathrm{degW}, 39 \mathrm{~m}$ a.s.l.) as obtained from the Global Historical Climatology Network (GHCN accessed on 10.3.2021; ). Precipitation sums from these records are strongly correlated $(0.80[?] \mathrm{r}[?] 0.97, \mathrm{p}<0.0001)$ with slightly higher values recorded in Ilulissat than suggested for the grid matching the research site. The resulting monthly temperature and precipitation records span the entire period of shrub growth (1892-2013) studied here.

\section{Climate-growth model comparisons}

To test the influence of seasonal climate on growth, linear mixed-effects model analyses were performed. In these, climate-growth models were compared with a null model. Before the analyses, both the climate and standardized individual shoot length series were normalized. This was done by subtraction of the mean of the series, followed by a division with the standard deviation. Annual shoot lengths of the individual branches were included in the models as the response variable. A total of 20 climate-growth models were compared with the null model. Mean temperatures or precipitation sums of the previous summer (June-August of the previous year), previous autumn (September-October of the previous year), early winter (NovemberDecember of the previous year), mid-winter (January-February), late winter (March-April), winter (previous November-April), spring (May), early summer (June-July), late summer (July-August), or summer (JuneAugust) sums were included as fixed effect. Furthermore, an autocorrelation structure (AR1, autoregressive process of order one) was included in each model to account for possible autocorrelation in the shoot length series. Random intercepts were included in the models foryear to account for spatially correlated environmental conditions not captured by the fixed effects. The null model was identical to the climate models with a mean of one instead of a climate variable as fixed effect. The linear mixed-effect model analyses were performed with the R-package nlme v.3.1-152 . Maximum likelihood estimation was used for model comparison and restricted maximum likelihood estimation was used to calculate slope estimates . Coefficients of determination values for each model were calculated using the r.squaredGLMM function of the MuMIn package v.1.43.17. The year 2014 was excluded from the analyses, as growth may not have been completed at the time of sampling in early August. The model comparison was done both at the site and shrub level. To test the stability of the climate-growth relationships over time, the model comparison was done for three different periods: the complete period (1893-2013), the most recent 50 years (1964-2013) as there was a clear increase in sample depth after 1964 (cf. Fig. 2) and the last complete climate period (1984-2013).

\section{Branch initiation and mortality frequencies}

Branch initiation and mortality frequencies were measured to test for links with climate. After cross-dating, in case the oldest part of a branch was intact with visible WMS, the year its initiation was recorded as the first calendar year of growth. This was possible for 717 of the 764 branches measured. In addition, the last year of growth was determined for 96 branches which had an intact dead tip, with dark-brown senesced primordial leaves. The first branch initiated in 1893. However, as for many years during the period 18931928 no branch initiations were recorded, branch initiation frequency analysis was restricted to the period 1929-2013. The oldest dead branch dated, died in 1966 (last year of growth) or before the growing season of 1967. Only four dead branches could be dated that had died before 1987/1988. Hence, branch mortality frequency analysis covered the period 1987-2013. Both frequency series contained trends caused by either low number of old branches and a bias towards analysis of longer branch series, i.e. relatively disregarding the shortest branches (cf. Fig. 3a), or by senescence and organic breakdown of dead branch tips, which easily break off, and a consequent quick decline of intact dead branches over time (cf. Fig. 3b). Therefore, both series were detrended with a cubic smoothing spline $2 / 3$ of the series length and a 50 percent frequency cut-off (Fig. 3ab).

Both the branch initiation and mortality series as well as the climate data were normalized by subtraction of the mean, followed by division with the standard deviation, before testing for possible links. For the latter Pearson's correlation coefficients were calculated. This was done between standardized branch initiation 
frequency and seasonal climate (mean temperatures and precipitation sums) from early summer prior to branch initiation to late summer of the year of initiation. In addition, correlation coefficients were calculated between standardized branch mortality frequency and seasonal climate from spring of the last year of growth to late winter after the last year of growth. The same definitions of seasons were used as for the climategrowth models (see above).

(a)

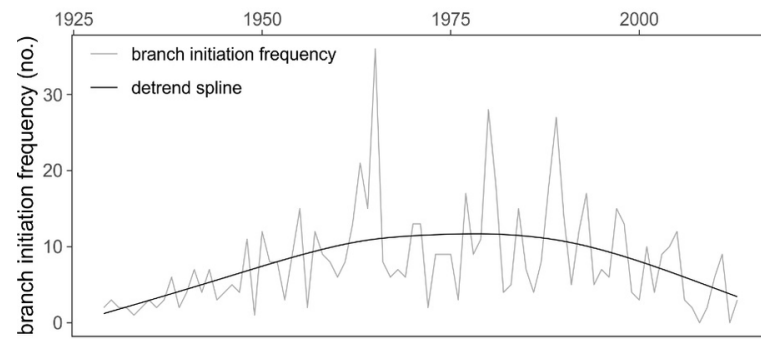

(c)

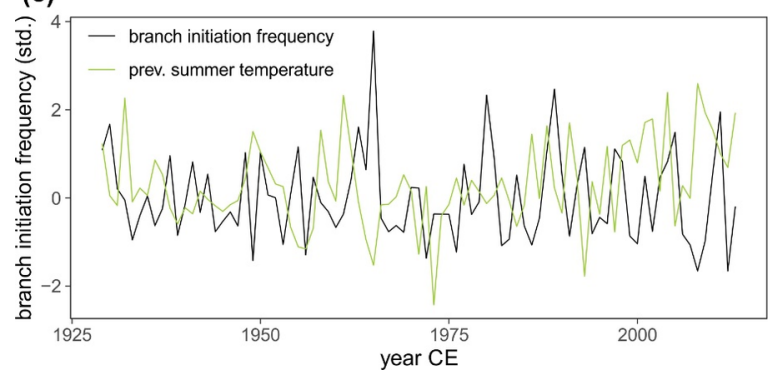

(b) branch mortality

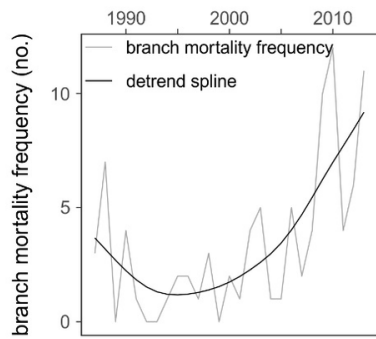

(d)

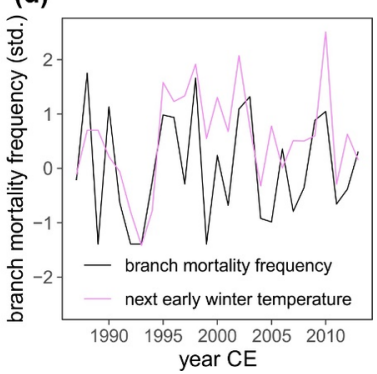

Figure 3 Branch initiation (a) and mortality (b) frequencies for the periods 1929-2013 and 1987-2013 respectively. The black lines represent the cubic smoothing splines $(2 / 3$ of the series length -50 percent frequency cut-off) with which the series were detrended. Standardized branch initiation frequency and previous summer (June-August) temperature $(\mathrm{r}=-0.23, \mathrm{p}<0.05)(\mathrm{c})$. Standardized branch mortality frequency and following early winter (November-December) temperature $(\mathrm{r}=0.59, \mathrm{p}<0.002)(\mathrm{d})$.

\section{NDVI}

Bi-weekly normalized difference vegetation index (NDVI) data for the approx. $8 \times 8 \mathrm{~km}^{2}$ pixel incorporating the research area was extracted from the third generation of the Global Inventory Modeling and Mapping Studies $\left(\mathrm{GIMMS}_{3 \mathrm{~g}}\right)$ dataset for the period July 1981 - 2015. The GIMMS $\mathrm{gg}_{\mathrm{g}}$-NDVI dataset is assembled from different sensors of the Advanced Very High-Resolution Radiometers (AVHRR) satellites. It was tested whether there were positive linear trends in maximum NDVI (NDVI max) and mean late summer (July-August) NDVI over time with one-sided Pearson's correlation tests. Furthermore, it was tested whether there were positive relationships between the mean standardized shoot length chronology / branch initiation on the one hand and NDVI $I_{\max }$ / late summer NDVI on the other. In addition, negative relationships between standardized branch mortality frequencies in the previous year and NDVI $\max$ / late summer NDVI were hypothesized and tested. Lastly, positive relationships between seasonal climate variables (mean temperatures and precipitation sums; the same as in the climate-growth models) were hypothesized and tested for significance with one-sided Pearson's correlation tests.

\section{Results}

\section{Shoot length series}

A total of 12,528 annual growth increments were measured of 764 branches and 25 shrubs, covering 122 years over the period 1893-2014 (Fig. 2, Table S1). Mean annual shoot length was $5.43 \pm 1.90 \mathrm{~mm}$ on site level and 
ranged between $4.26 \pm 2.10 \mathrm{~mm}$ and $10.20 \pm 3.86 \mathrm{~mm}$ between shrubs (Table S2). Individual shrub series spanned between 59 (1956-2014) and 122 (1893-2014) years (Fig. S2, Table S2). There were clear similarities in growth variations over time between branch series, especially within, but also between shrubs, as shown by the mean interseries correlation coefficients of 0.53 and 0.42 , respectively. The Gini coefficient was 0.19 across all specimen, suggesting intermediate variability in growth, comparable to that found for the same species in the polar desert in northern Greenland. Gini coefficients at the shrub level varied between 0.16 and 0.28 , suggesting intermediate to high variability of growth of individual shrubs in comparison to variation in tree-ring widths from mesic to xeric sites .

Climate-growth: site level

The climate-growth model comparison calculated at the site level over the entire period (1893-2013) indicated that summer temperatures were the main limiting climate factor for annual shoot length growth ofCassiope tetragona at the research site on Disko Island, Greenland (Table 1, Fig. 4). Higher summer temperatures led to longer shoot length increments (slope: $0.25 \pm 0.03$ ). The winter temperature model (slope: $0.12 \pm$ 0.04) was the best non-summer model at the site level over this period, suggesting a positive influence of winter temperatures on growth. The site-level climate-growth model comparison computed over 1964-2013 gave similar results (Table S3). The mean summer temperatures plotted together with mean site level shoot length (Fig. 4a) show that summer temperature and shoot length generally fluctuated in the same direction from year-to-year. However, growth did not keep up with extreme summer temperatures, especially during the warm summers of the late 1940s, early 1960s and in recent decades. The site level model comparison over 1984-2013 showed that summer temperatures were still the most limiting climate factor for growth during this period, although mean late summer (July-August) temperatures became more important than mean summer (June-August) temperatures. Notably, the slopes of the summer temperature models calculated over the recent period (1984-2013) are lower than those calculated over the complete period (1893-2013). The early summer precipitation model was the only non-summer temperature model with [?]AIC $>2$, suggesting that June-July precipitation sums have been a limiting factor for shoot length growth at the site level during 1984-2013.

Table 1 Statistics of the selected climate-growth models ([?]AIC $>2$ ) at the site level calculated over the periods 1893-2013 (a) and 1984-2013 (b). AIC, Akaike Information Criterion; SE, standard error; $\mathrm{mR}^{2}$, marginal coefficient of determination (proportion of variance explained by fixed effect); $\mathrm{cR}^{2}$, conditional coefficient of determination (proportion of variance explained by fixed and random effects); T, mean temperature; P, precipitation sum; prev., previous.

\begin{tabular}{lllll}
\hline 1893-2013 & & & & \\
\hline model & {$[?] \mathbf{A I C}$} & Slope $\pm \mathbf{S E}$ & $\mathbf{m} \boldsymbol{R}^{\mathbf{2}}$ & $\mathbf{c R}^{\mathbf{2}}$ \\
summer T & 49.63 & $0.25 \pm 0.03$ & 0.07 & 0.17 \\
early summer T & 44.64 & $0.24 \pm 0.03$ & 0.06 & 0.17 \\
late summer T & 36.76 & $0.22 \pm 0.03$ & 0.06 & 0.17 \\
winter T & 6.23 & $0.12 \pm 0.04$ & 0.01 & 0.16 \\
prev. fall P & 5.18 & $0.10 \pm 0.04$ & 0.01 & 0.17 \\
early winter T & 5.15 & $0.10 \pm 0.04$ & 0.01 & 0.16 \\
mid-winter T & 3.99 & $0.10 \pm 0.04$ & 0.01 & 0.16 \\
prev. summer T & 3.36 & $0.09 \pm 0.04$ & 0.01 & 0.16 \\
(b) 1984-2013 & & & & \\
model & {$[?] \mathbf{A I C}$} & $\mathbf{S l o p e} \pm \mathbf{S E}$ & $\mathbf{m} \boldsymbol{R}^{\mathbf{2}}$ & $\mathbf{c} \boldsymbol{R}^{\mathbf{2}}$ \\
late summer T & 5.78 & $0.18 \pm 0.06$ & 0.04 & 0.18 \\
summer T & 4.42 & $0.17 \pm 0.07$ & 0.03 & 0.18 \\
early summer T & 2.76 & $0.15 \pm 0.07$ & 0.03 & 0.18 \\
early summer P & 2.32 & $0.20 \pm 0.09$ & 0.02 & 0.18 \\
\hline
\end{tabular}


(a)

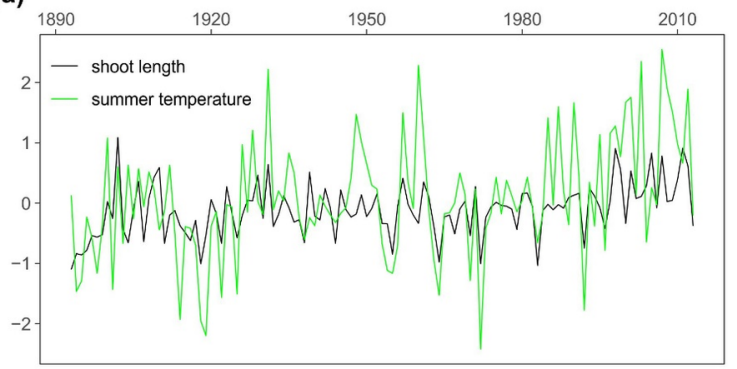

(c)

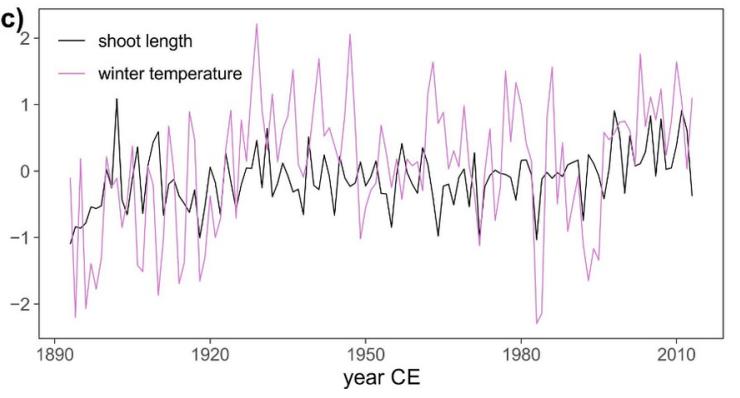

(b)

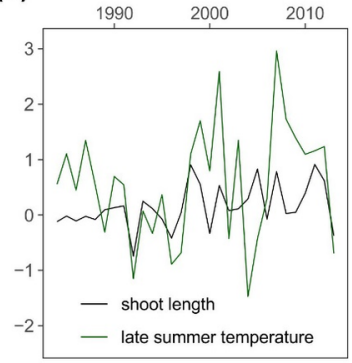

(d)

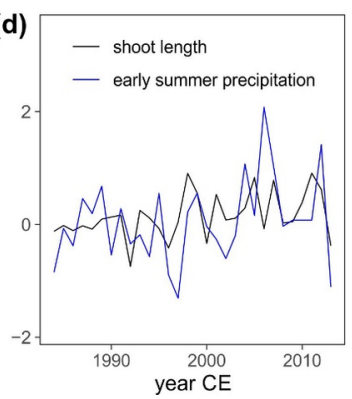

Figure 4 Mean shoot length with the fixed factor of the best climate model at the site level calculated over the periods 1893-2013 (a) and 1984-2013 (b), and with the best non-summer temperature model over the periods 1893-2013 (c) and 1984-2013 (d). All parameters shown are standardized (z-scores).

\section{Climate-growth: shrub level}

A similar picture emerged from the climate-growth model analyses on the individual shrub level (Table S4, Figs S4 and 5). Computed over the complete period (1893-2013), all shrubs had a summer climate model as best model. The summer temperature model was the best model for $12 / 25$, the late summer temperature model for $8 / 25$, and the early summer temperature model for $4 / 25$ shrubs. For one shrub, the previous summer precipitation model was the best model. All best models had a positive slope, which ranged between 0.15 and 0.37 (Table S4a). For 14/25 shrubs sampled, non-summer climate models had a [?]AIC $>2$, 11 of which were winter temperature models: growth of five shrubs responded to winter (November - April), three to early winter (November - December), and three to late winter (March - April) temperatures. All winter temperature models had a positive slope (between 0.18 and 0.33; Table S4a), suggesting a beneficial effect of higher winter temperatures preceding the growing season on shoot length development at the study site for 11 shrubs. Climate in spring (May) was found to be the best non-summer climate model for two of the shrubs: May temperature for one and May precipitation for the other. Both these models had a positive slope. Winter precipitation had a negative impact on shoot length of one of the shrubs (DI25), which otherwise pre-dominantly responded to late summer temperature. The model comparison calculated over 1964-2013 at the individual shrub level produced comparable results (Table S5). As seen on the site level, annual shoot length growth of many individual shrubs tracked year-to-year variability in summer temperatures during most years with divergence during warm extremes in recent decades, as well as earlier periods (Figures S4a and S5). There was a spatial pattern visible in the distribution of shrub response to summer climate, with shrubs responding to early summer temperatures confined to up-slope positions, a late summer temperature response found mostly downslope, and a summer temperature response in between and at overlapping positions with either (Fig. 5a).

Summer temperature models best explained growth for $12 / 25$, i.e. less than half of the shrubs, when the analysis was performed over the period 1984-2013 (Table S4b, Fig. S4b). Shoot length growth of seven shrubs responded to late summer (July-August) temperature and that of five to summer (June-August) temperature. These summer temperature models had a positive slope, which ranged between 0.17 and 0.34 
(Table S4b). For $5 / 25$ shrubs, the early summer precipitation model was the best model (slope between 0.25 and 0.38 ). For $4 / 25$ shrubs, a non-summer climate model was the best model. For two shrubs, early or late winter temperature models best explained shoot length growth. Both models had a positive slope. Two other shrubs showed a negative response to previous fall temperatures (Table S4b). Four of the 25 shrubs did not respond to climate over this period. Over 1984-2013, non-summer climate models had a [?]AIC>2 for $11 / 25$ shrubs, 7 of which were winter temperature models: one early (prev. November- prev. December), three late (March-April) and three winter (prev. November-April) temperature models, all with a positive slope (Table S4b). Three shrubs showed a negative response to previous fall temperatures. In contrast to the calculation over 1893-2013, in the recent period (1984-2013) late winter precipitation had a positive impact on shoot length of one of the shrubs (DI24), which pre-dominantly responded to late summer temperature. Shrubs with a non-summer model as best model and non-responsive shrubs were generally positioned further upslope (Fig. 5c), as were shrubs with previous fall temperature as best non-summer model (Fig. 5d).
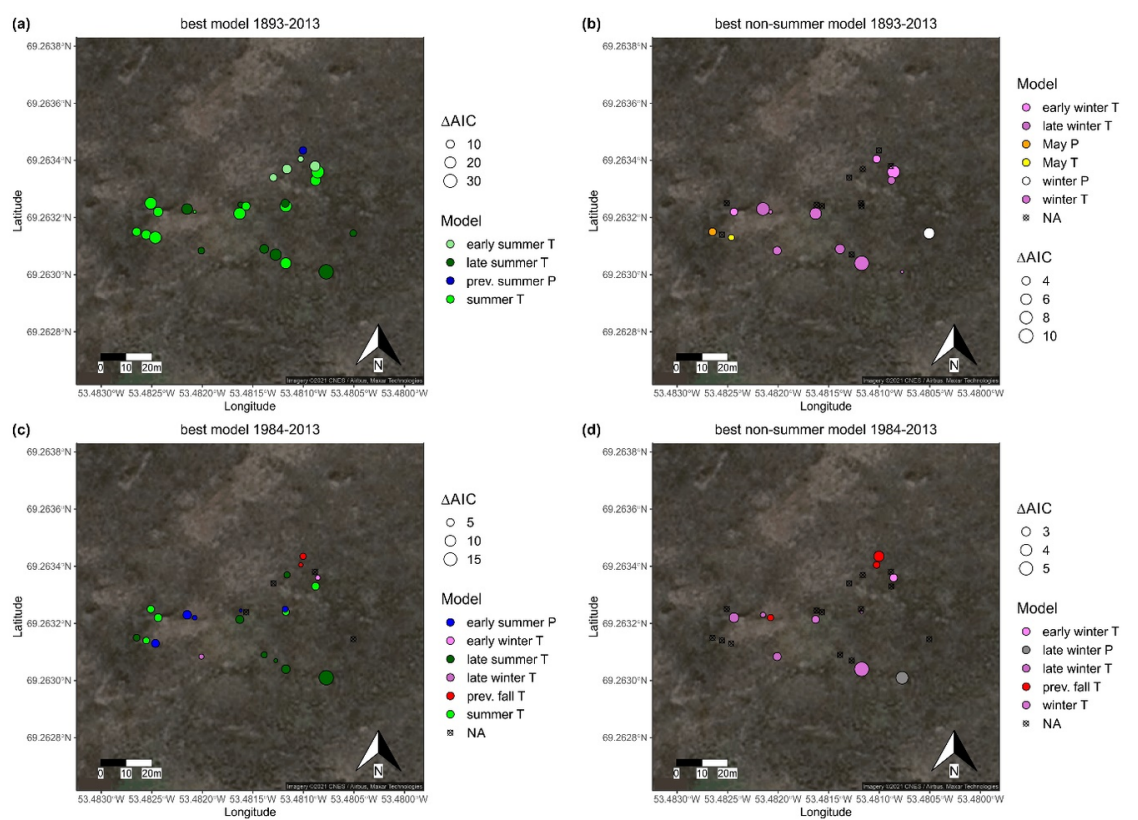

\section{Branch initiation and mortality}

Over the period studied (1929-2013) branch initiation frequency was negatively correlated with mean summer temperatures in the year prior to branch initiation $(\mathrm{r}=-0.23, \mathrm{p}<0.05$; Fig. $3 \mathrm{c})$, i.e. warm summers were linked with a lower amount of new branches formed in the year after. Over the period 1987-2013, branch mortality frequency was positively correlated with mean early winter temperatures following the growing season in the year of death $(\mathrm{r}=0.59, \mathrm{p}<0.002$; Fig. 3d) and with mean temperatures in spring prior to the growing season $(0.50, \mathrm{p}<0.01)$. Higher temperatures before and after the growing season were thus related with higher branch mortality.

\section{NDVI}

Standardized mean site-level shoot length growth was positively correlated with late summer (July-August) NDVI $\left(\mathrm{r}=0.44, \mathrm{p}<0.01\right.$, Fig. 6a) as well as $\mathrm{NDVI}_{\max }(\mathrm{r}=0.40, \mathrm{p}<0.05)$. There was a weak link between standardized branch initiation and $\mathrm{NDVI}_{\max }(\mathrm{r}=0.26, \mathrm{p}<0.1$; Fig. $6 \mathrm{~b})$. There were no negative correlations between standardized branch mortality frequency and NDVI in the research area. There was a slight positive trend in late summer NDVI over the period 1981-2013 ( $\mathrm{r}=0.24, \mathrm{p}<0.1$; Fig. 6a), but not in $\mathrm{NDVI}_{\max }$.

Late summer NDVI and $\mathrm{NDVI}_{\max }$ were positively related to summer and, notably, winter temperatures 
(Table 3). Furthermore, there were positive relationships between late summer NDVI and spring precipitation sums, and weakly, late winter precipitation sums (Table 3 ).
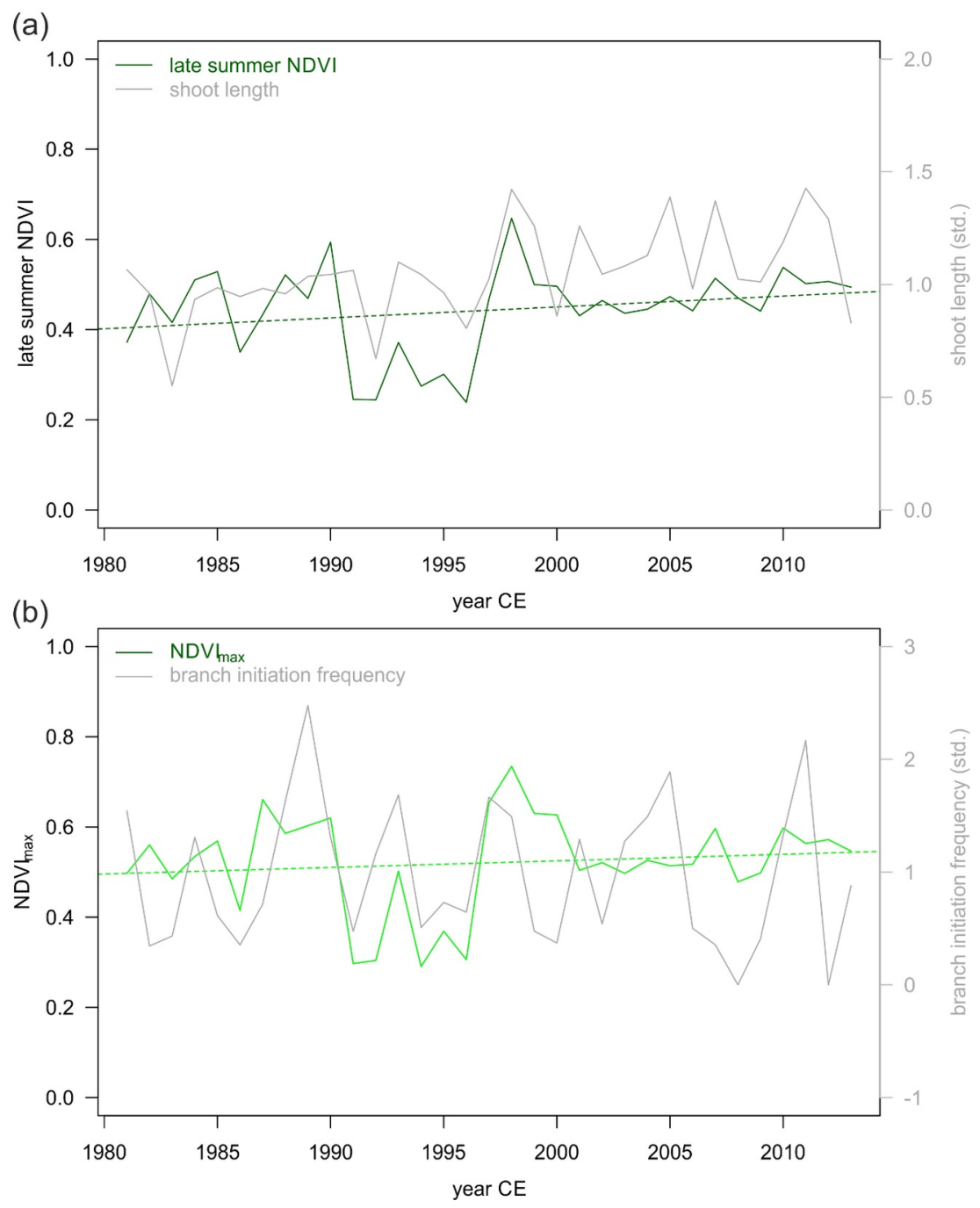

Figure 6 Standardized mean shoot length site-chronology and mean late summer (July-August) NDVI over 1981-2013 ( $\mathrm{r}=0.44, \mathrm{p}<0.01)$ (a). There was a positive trend in late summer NDVI over this period $(\mathrm{r}=0.24$, $\mathrm{p}<0.1)$. Standardized branch initiation frequency and maximum NDVI $(\mathrm{r}=0.26, \mathrm{p}<0.1)(\mathrm{b})$.

Table 3 Pearson correlation coefficients between climate variables and late summer (July-August) NDVI/ maximum NDVI over the research area. Only coefficients with $\mathrm{p}<0.1$ are shown. $\mathrm{p}<0.1,{ }^{*} \mathrm{p}<0.5,{ }^{* *} \mathrm{p}<0.01$.

\begin{tabular}{lll}
\hline variable & late summer NDVI & $\mathrm{NDVI}_{\max }$ \\
\hline summer $\mathrm{T}$ & $0.47^{* *}$ & $0.48^{* *}$ \\
early summer $\mathrm{T}$ & $0.45^{* *}$ & $0.44^{* *}$ \\
late summer T & $0.40^{*}$ & $0.35^{*}$ \\
late winter $\mathrm{T}$ & $0.32^{*}$ & 0.25
\end{tabular}




\begin{tabular}{lll}
\hline variable & late summer NDVI & $\mathrm{NDVI}_{\max }$ \\
\hline spring $\mathrm{P}$ & $0.30^{*}$ & - \\
winter $\mathrm{T}$ & $0.30^{*}$ & 0.26 \\
late winter $\mathrm{P}$ & 0.26 & - \\
early winter $\mathrm{T}$ & 0.23 & - \\
\hline
\end{tabular}

\section{Discussion}

\section{Temperature-growth decoupling}

The shoot length growth response to summer temperatures of Cassiope tetragona at the site level over the entire period studied (1893-2013) can be classified as highly sensitive ([?]AIC = 49.63; cf. ). However, in recent decades (1984-2013) this sensitivity can be categorized as low ([?]AIC $=5.78$ ) and it was completely absent for over half of the individuals studied, as shown by the analyses on individual shrub level. While late summer (July-August) temperatures were the most limiting factor for growth at the site level over the period 1984-2013, early summer precipitation was identified as an important co-driver of growth at the site level and as the most limiting factor for 20 percent of the individuals studied here. A similar divergence between growing season temperatures and evergreen dwarf shrub growth has recently been demonstrated in the French Alps for the species Rhododendron ferrugineum .

The observed lower sensitivity of shrub growth to summer temperature in recent decades was probably caused by the on average warmer summers during this period $\left(7.13{ }^{\circ} \mathrm{C}\right.$ in $1984-2013$ vs. $6.40{ }^{\circ} \mathrm{C}$ in $1893-$ 1983, p<0.001; Fig. S6). This, in combination with the observed non-linear growth response to summer temperatures, with a smaller, lack of, or even negative response to mean summer temperatures exceeding a threshold of approx. $7{ }^{\circ} \mathrm{C}$ (Fig. S5). Although the shrubs were capable of maintaining high levels of shoot length growth in summers with mean temperatures exceeding this threshold, other factors than summer temperature became more limiting for the majority of the shrubs studied. Interestingly, reported a weakening in temperature-growth relationships in Betula nana and Salix glauca shrubs in more continental Greenland, $272 \mathrm{~km}$ southeast of Disko Island, when summer (there: May-August) temperatures passed a threshold of approx. $7^{\circ} \mathrm{C}$. A similar non-linear response of C. tetragona shoot length growth was observed over a gradient of growing degree-day sums ( $\mathrm{GDD}_{5}$; cumulative daily mean temperatures above $\left.5{ }^{\circ} \mathrm{C}\right)$ across three sites, two in High Arctic Svalbard, one in Sub-Arctic Sweden . It is, therefore, likely that this evergreen dwarf shrub species will not be able to respond with increased growth rates to warmer summers in the Low and SubArctic under future global warming. This may lower its competitiveness, especially for light, in relation to taller deciduous shrub species, which are migrating into tundra ecosystems. However, growth of such species has been shown to be less sensitive to warming at drier sites, than at moister sites. The dwarf shrub $C$. tetragona, on the other hand, is restricted to relatively dry soils and adapted to dry conditions with its xeromorphic leaves. Therefore, it may remain competitive in drier habitats.

In this study, a positive influence of summer precipitation on growth of $C$. tetragona was detected for some of the shrub individuals studied here over the period 1984-2013. Summer precipitation was observed to be a co-driver of $C$. tetragona growth for one of four sites on Ellesmere Island in High Arctic Canada . However, a similar influence had not yet been observed for this species at other sites. Not at relatively warm tundra sites in the Sub-Arctic (; ), nor in the High Arctic , including the northernmost polar desert in northern Greenland. In addition, C. tetragona growth did not respond to experimentally doubled summer precipitation in High Arctic Svalbard. The reason for a lack of detection of a summer precipitation signal in other Arctic sites could be (micro)site-specific. Soil moisture availability may be largely decoupled from summer precipitation and instead determined by downslope meltwater run-off, active layer thaw, and low evapotranspiration rates in the High Arctic . At Arctic-alpine sites with late snow cover, where the species is found, snowmelt likely provides sufficiently high soil moisture levels throughout the growing season. In addition, at other sites, climate-growth relationships have not been assessed at the individual level and sensitivity to precipitation may not only be site-specific, but also micro-site specific, due to, for example 
greater soil moisture availability in small depressions or snow accumulation behind rocks. Remarkably, two of the shrubs studied here (DI15 and DI16) grew near rocks and their growth remained sensitive to summer temperatures in recent decades (Fig. S4). Furthermore, climate-growth links have mostly solely been studied over longer periods, and did not focus on the recent warm period. However, growth of the deciduous dwarf shrub Betula nana in the northeastern Siberian tundra was shown to be sensitive to summer precipitation in warm, but not in cool summers. In addition, shoot length growth of $C$. fastigiata was detected to be sensitive to moisture availability in the tree-line ecotone and growth ofJuniperus indica shrubs was found to be driven by early growing season precipitation, both in the central Himalayas of Nepal. In addition, low amounts of summer precipitation as a co-determinant of drought conditions has been shown to indirectly drive declining deciduous shrub growth at drier sites, while summer temperature drives increasing deciduous shrub growth at wetter sites in the Arctic .

\section{Influence of winter temperatures}

Winter temperatures preceding the growing season were observed to be the main co-driver of $C$. tetragona growth at the site level and for 11/25 shrubs studied over the period 1893-2013. In recent decades, it was found to be a co-driver for five shrubs and the main climatic driver for two. Notably, a similar positive effect of warm winters on dwarf shrub growth was observed for the deciduous dwarf shrub Betula nana at an adjacent site on Disko Island. In their study, the positive effect of winter temperatures on growth was interpreted as a result of warmer winters and related spring air temperatures causing snow to melt out earlier, allowing soils to drain and warm faster. This then results in longer growing seasons, leading to increased growth. For C. tetragona at the study site this mechanism is less plausible, as early summer temperatures were the main climatic driver of only four shrubs (1893-2013) and of none in recent decades. This suggests that this species may not benefit from earlier snow melt-out, which is in line with the observation that $C$. tetragona growth benefits from warmer Julys, but not from longer growing seasons near its European southern distribution limit in Abisko, Sweden . An alternative explanation could be grounded on the fact that winter air temperatures are positively related to winter precipitation sums in Disko Island (Figs S7 and S8). In warmer winters, an increase in winter snow precipitation may result in a deeper snowpack and higher winter soil temperatures due to insulation. Moreover, in recent decades winter soil temperatures have been directly coupled with winter air temperatures in the area. Warmer winter soil temperatures may be linked to higher microbial activity in winter and result in greater nutrient availability in the subsequent growing season and hence support increased shrub growth. In addition, warm winters are negatively linked with sea ice extent in the Disko Bay area and earlier sea ice retreat leads to warmer summers. This may explain the positive correlation between (late) winter and summer temperatures at the site (Figs S7 and S8) and partly or alternatively explain the observed association between winter temperatures and C. tetragona growth. A similar possible link between sea-ice conditions prior to the growing season, summer temperatures, and $C$. tetragona growth has previously been suggested in northern Greenland .

\section{Micro-topography}

Shrubs responsive to early summer temperatures were restricted to upslope positions, while those responsive to late summer temperatures were found further downslope. This pattern may be related to the redistribution of snow by wind with accumulation of snow according to topography . In the study area, winter winds blow mainly from northern direction, and the downslope positions may thus be more wind-sheltered and be covered in a deeper snow layer. Upslope positions would then be snow-free earlier, which may explain the responsiveness to early summer temperatures found there. Upslope soils will drain and warm faster and are thus drier, which could be the reason for the response to previous summer precipitation of the northernmost shrub in this study. This could also explain the negative response to previous autumn temperatures over the period 1984-2013 of some of the upslope shrubs, with warm dry autumns resulting in lower soil moisture availability in the following growing season. A negative influence of autumn temperatures was recently also observed for shoot length growth of the related boreal shrubEmpetrum nigrum , growing near its southern lowland distribution limit in northern Germany . Over the period 1984-2013, non-responsive shrubs were mostly found at upslope positions and shrubs responsive to early summer precipitation sums mostly mid- 
slope. Shrubs at downslope positions were mostly still responsive to late summer temperatures. This is in line with the expected gradient in snow depth.

\section{Branching and branch mortality}

Warm early winters (November-December) after the growing season may have led to higher branch mortality rates. In years with high branch mortality, hourly temperatures were in general more frequently above freezing point in November-December than in years with low branch mortality (Fig. S9). Such winter warming events can cause reduced snow cover leaving the plants vulnerable to subsequent freezing damage and dieback, as observed for C. tetragona in Svalbard . Moreover, winter warming often coincides with rain-on-snow events , the frequency of which has increased in Greenland in recent decades . Such events can lead to encasement of plants in ground-ice, which increases branch mortality in C. tetragona, as has been shown experimentally in Svalbard . In the same icing-experiment, it was found that shoot length of surviving branches increases after icing treatment. This may offer an additional or alternative explanation for the positive influence of winter temperatures on C. tetragona observed here.

Warm springs (Mays) prior to the growing season may have resulted in increased branch mortality, following a similar mechanism. Spring warming may lead to an advanced start of the growing season. This can leave plants exposed to late frost, which can result in damage to soft tissues and reduced growth, as was observed the evergreen shrubsEmpetrum nigrum ssp. hermaphroditum, at a near tree-line site in the Central Norwegian Scandes and Rhododendron ferrugineum at a low-alpine site in the French Alps .

Branching occurred more often after years with cool summers than after years with warm summers. There was also a negative correlation between shoot length growth in the previous year and branch initiation frequency $(\mathrm{r}=-0.21, \mathrm{p}<0.05)$. Hence, when shoot length growth in the previous growing season is below average, perhaps due to a cool summer, $C$. tetragona shrubs tend to invest more in new branches to increase or maintain its photosynthetic capacity. observed an increase in the number of branches in C. tetragona shrubs in response to experimental shading. Similarly, the shrubs seem to form more side-branches after recent stress, such as damage to branch tips (own observation). Dead or damaged C. tetragona shoot tips with a cluster of new branches are also a remarkable feature of shrubs exposed to experimental icing . Likewise, browsing by ptarmigan and moose leads to increased production of vegetative shoots in the deciduous tall shrubSalix alaxensis in northern Alaska. The capacity of making new branches, sometimes, though rarely, on decades-old $C$. tetragonastem segments, may be related to their presence at the basal part of annual shoot increments, i.e. near WMS, which consist of green meristem tissue. C. tetragona may thus be well-adapted to and capable of recovery from branch dieback caused by winter warming events, as its primordia are often protected under old leaves at lower stem positions.

\section{Correspondence between growth, branching and NDVI}

Annual variation in C. tetragona shoot-length growth and branching frequency positively related to fluctuations in satellite-observed vegetation greenness over the research area. This suggests that there is, at least to some degree, correspondence in annual variation in community-level vascular plant biomass. This is in line with, who found that annual growth of this species represents annual above-ground tundra vegetation productivity at the local scale. Moreover, the same climate variables, i.e. summer and winter temperatures, as observed for the evergreen dwarf shrub C. tetragona drove year-to-year satellite-observed variation in greenness. The same climate parameters determine growth rates of the co-dominant deciduous dwarf shrub B. nana in the research area in the Blæsedalen valley on Disko Island . Such similarity in climatic drivers of growth patterns between shrub species with contrasting life strategies and NDVI was earlier observed over Arctic-alpine areas in northwest North America . The lack of a link between branch mortality and NDVI may be due to increased branching after winter warming events. Satellite-observed vegetation productivity in the research area did not correlate with early summer precipitation, but there were positive relations with late winter and spring precipitation. Growth and productivity of the shrub-dominated vegetation in the Blæsedalen valley may thus be increasingly moisture-limited. It is, however, not in decline, as observed for B. nana and S. glauca in a warmer and drier area on the mainland of Greenland, approx. $270 \mathrm{~km}$ 
south-southeast of Disko Island. While there was a slight increasing trend in late summer NDVI, there was no trend in $\mathrm{NDVI}_{\max }$, which is in line with the widespread vegetation stability observed over large parts of the Arctic .

\section{Conclusions}

Since at least the late $19^{\text {th }}$ century, summer temperatures have been the main climatic driver of growth of the evergreen dwarf shrub Cassiope tetragona at the Low Arctic research site near Qeqertarsuaq on the southern tip of Disko Island, western Greenland. Winter temperatures have been a co-driver of shrub growth. In recent and past warm decades, however, shrub growth has diverged from summer temperatures. For some individual shrubs, apparently mostly those growing at positions with lower soil moisture availability as determined by micro-topography, early summer precipitation has become the main driver during the recent climatic period (1984-2013), while over half of the shrubs studied became insensitive to summer temperatures. The correspondence between climatic drivers, C. tetragona growth and branch initiation frequency, and satelliteobserved vegetation productivity (NDVI), suggests that the climate-growth observations for C. tetragona at least partly apply to the entire shrub-dominated vegetation in the research area. Winter warming events are likely the most prevalent cause of branch mortality in C. tetragona. Increased branching after years with poor growth and cooler than average summers, seems related to stress and may enable the shrub to overcome damage, for example, caused by winter warming events.

These findings suggest that erect dwarf-shrub tundra in the Low Arctic will likely become decreasingly temperature- and increasingly moisture-limited under future warming and that, although winter warming supports shrub growth, increased frequency of extreme winter warming events will likely lead to increased branch mortality and damage the dwarf shrub tundra. The observed divergence between summer temperatures and shrub growth during warm phases and the contrasting, potentially balancing effects of warmer winter temperatures may offer a mechanistic explanation for the still widespread stability of Arctic tundra vegetation.

\section{Acknowledgements}

Fieldwork for this study, including travel to and stay at Arctic Station was funded through the transnational access program INTERACT - International Network for Terrestrial Research and Monitoring in the Arctic. I am grateful to the Government of Greenland for sampling permission. I express my thanks to Anders Michelsen and Daan Blok for support with fieldwork preparation and sample transport. I thank Lennard van Rij for field assistance and Till Groh for lab assistance.

\section{Authors' contributions}

SW conceived and designed the study, performed the analyses and wrote the manuscript.

\section{Conflict of Interest}

There is no conflict of interest.

\section{Data Accessibility}

- Shoot length data will be made available at DataDryad.org upon acceptance of the manuscript for publication.

- Hourly air temperatures from ClimateBasis Disko: GEM database: https://data.g-e-m.dk

- Ilulissat homogenized monthly temperatures: https://crudata.uea.ac.uk/cru/data/greenland/

- CRU TS4.04: https://crudata.uea.ac.uk

- Ilulissat monthly precipitation sums: Global Historical Climatology Network (GHCN): https://www.ncei.noaa.gov

- Bi-weekly normalized difference vegetation index (NDVI) data from the Global Inventory Modeling and Mapping Studies (GIMMS3g) dataset: http://poles.tpdc.ac.cn/en/data/9775f2b4-7370-4e5e-a537$3482 \mathrm{c} 9 \mathrm{a} 83 \mathrm{~d} 88 /$ 

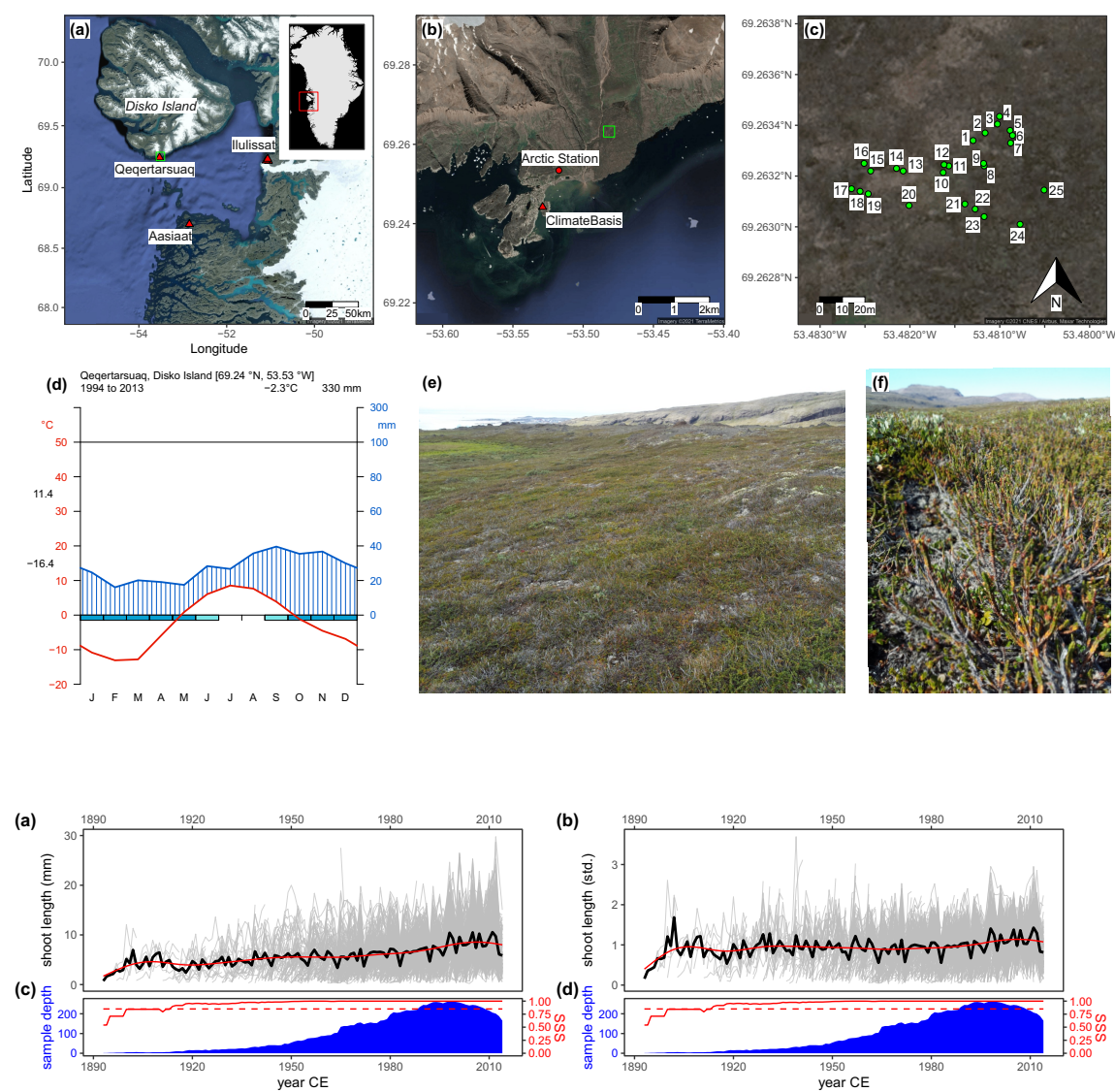

(a)

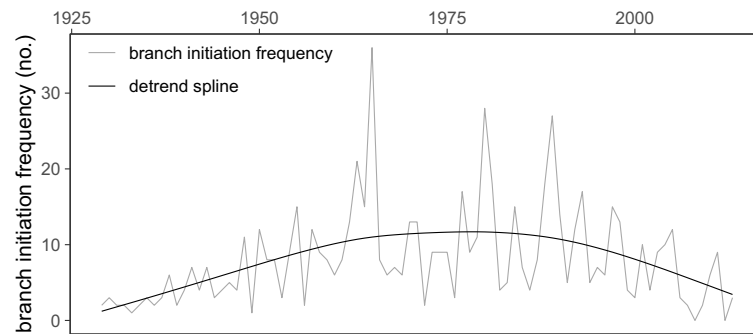

(c)

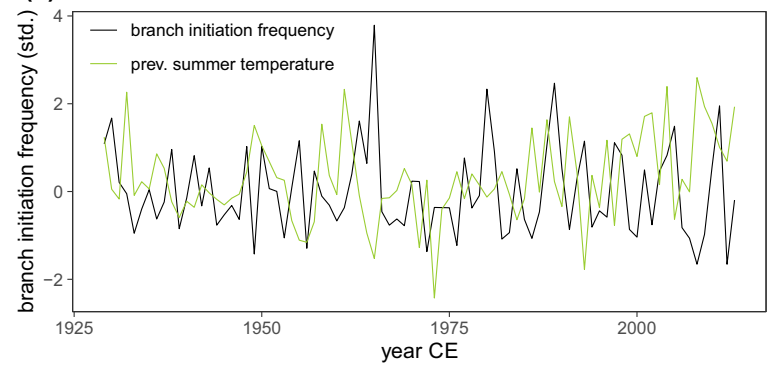

(b) branch mortality

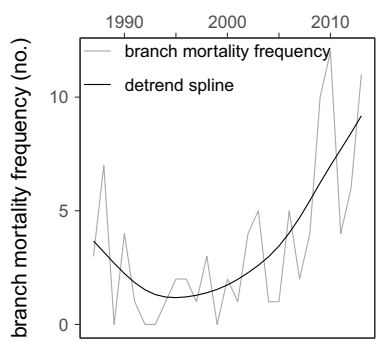

(d)

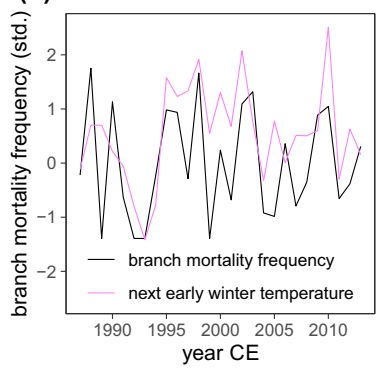


(a)

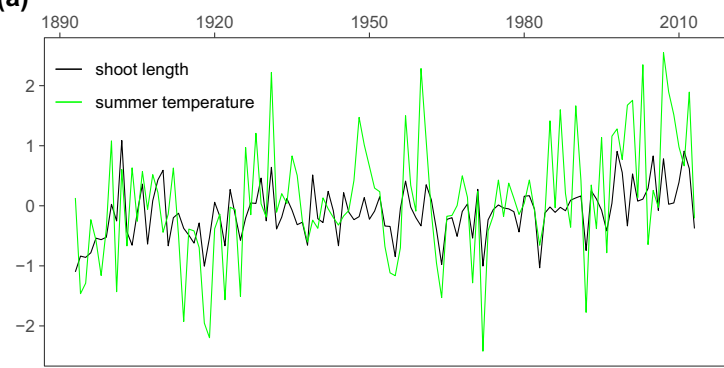

(c)

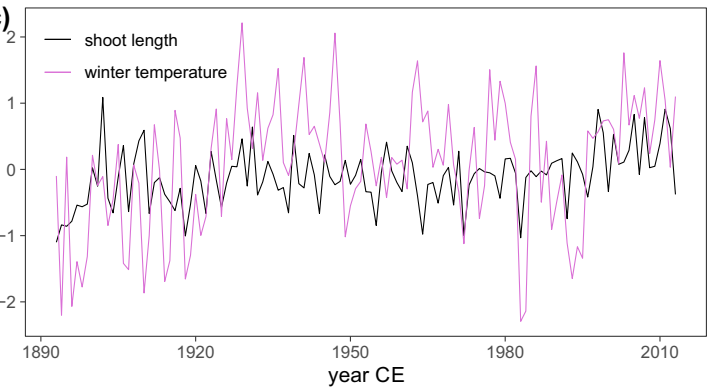

(b)
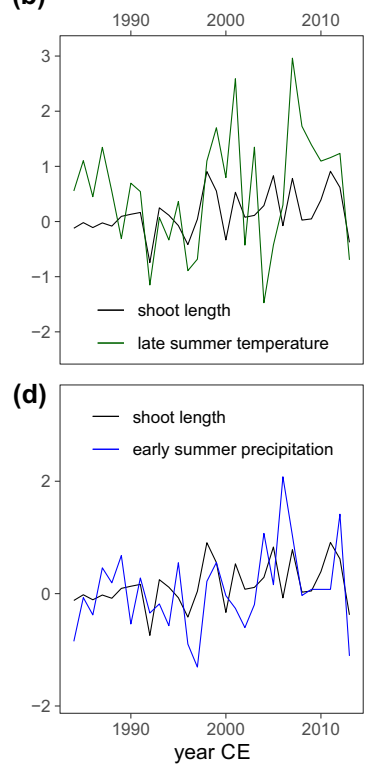

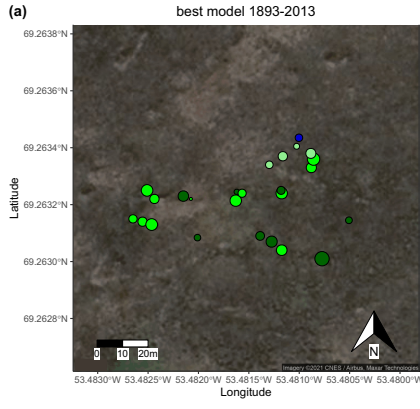

(c)

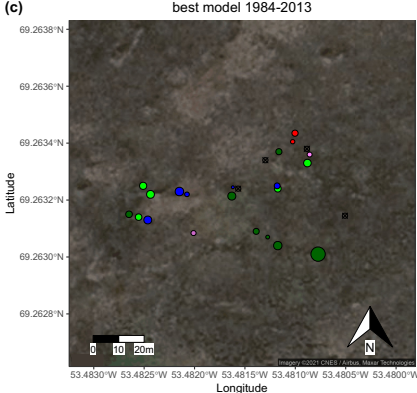

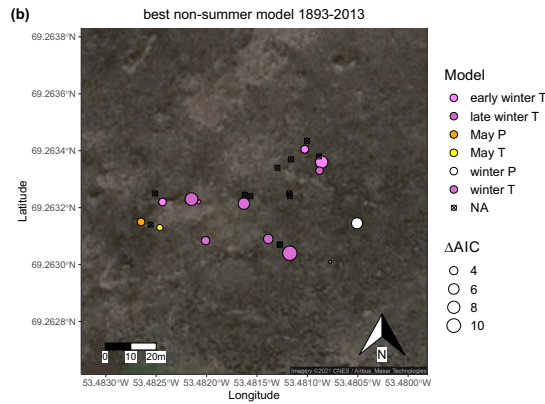

(d)

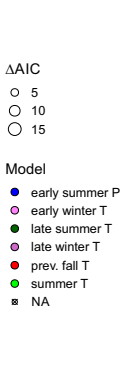

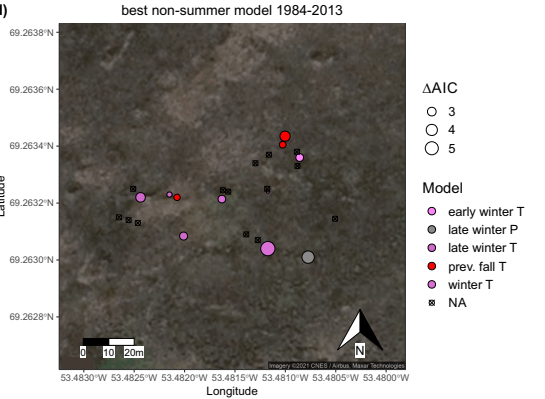


(a)
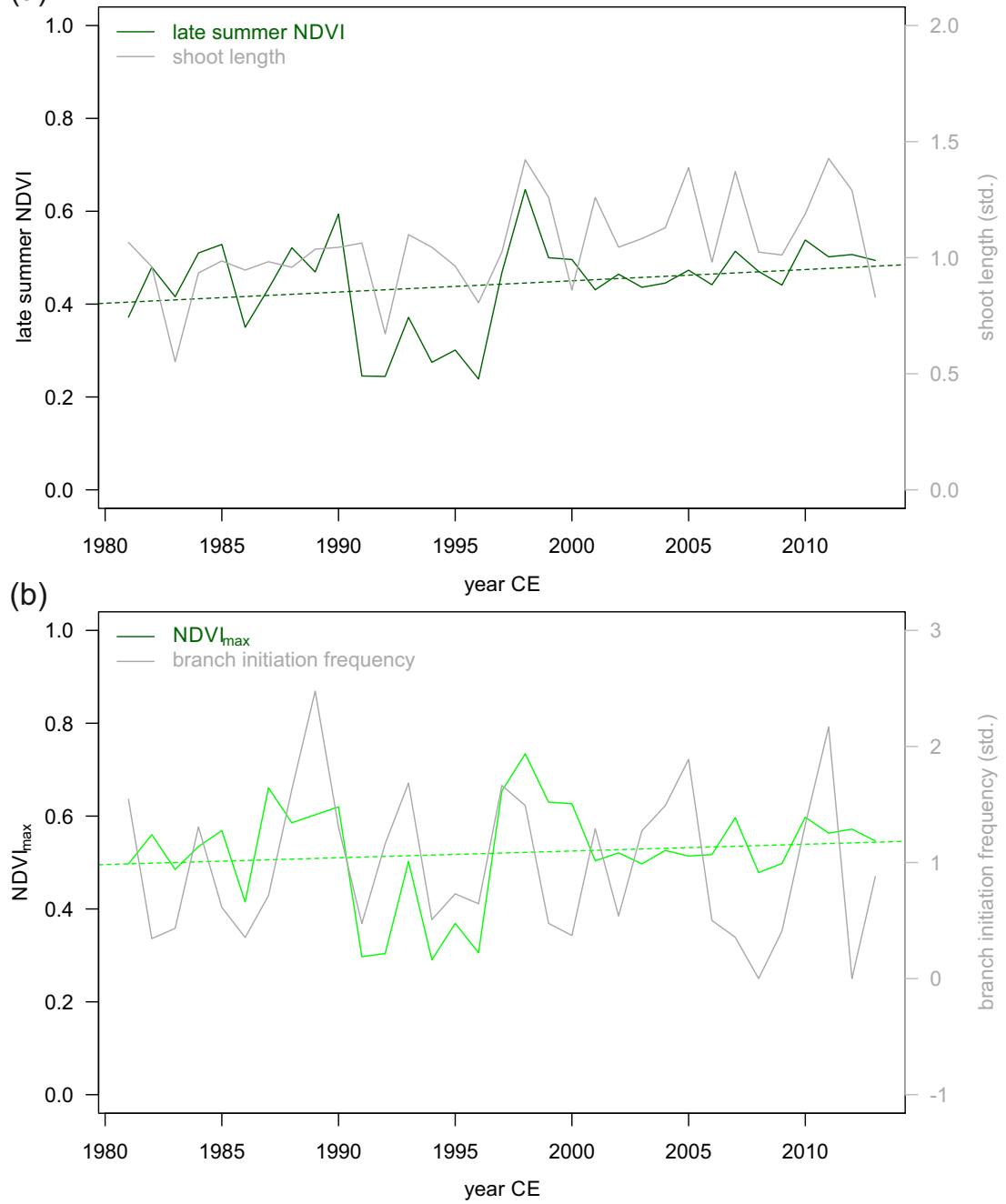

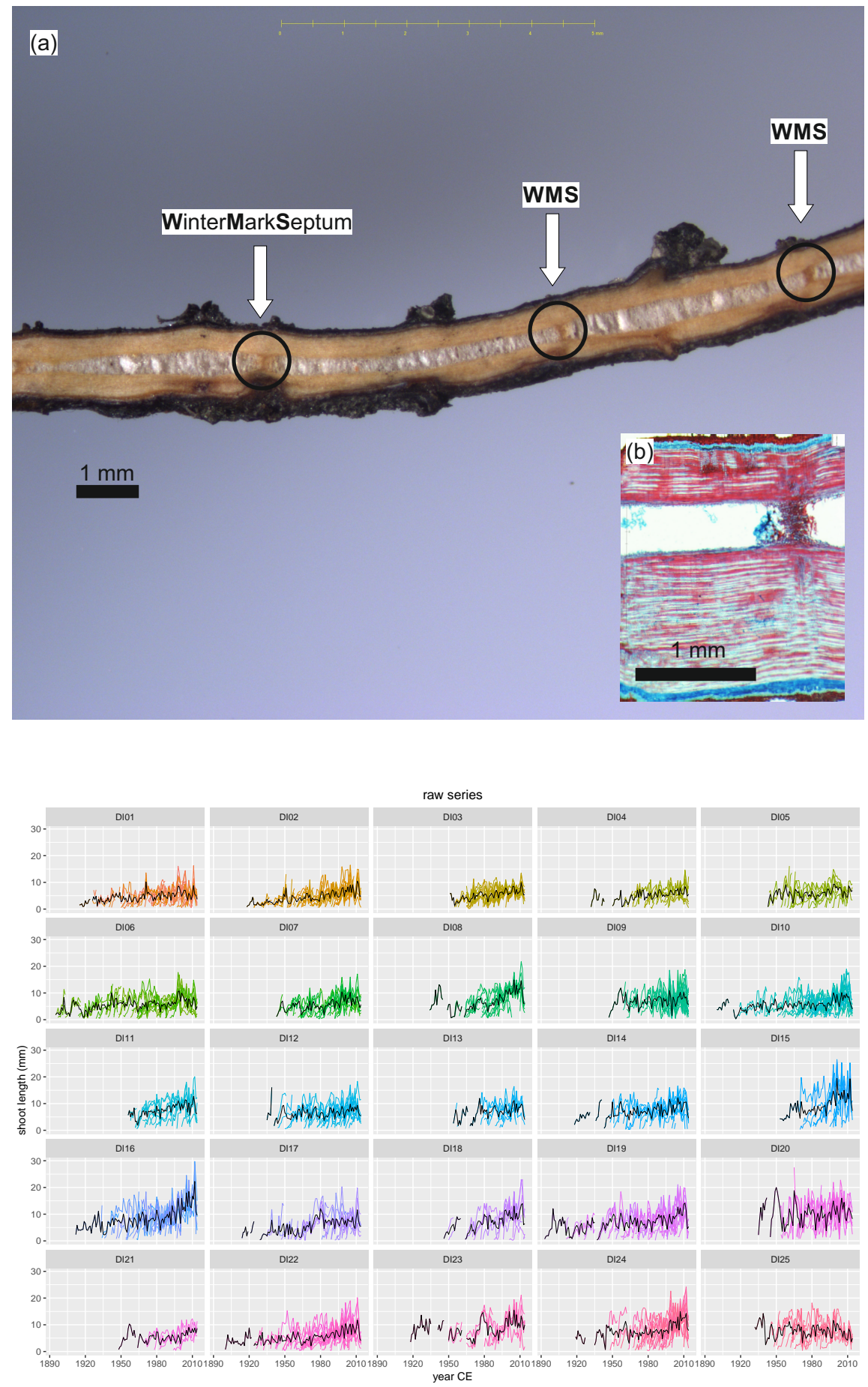


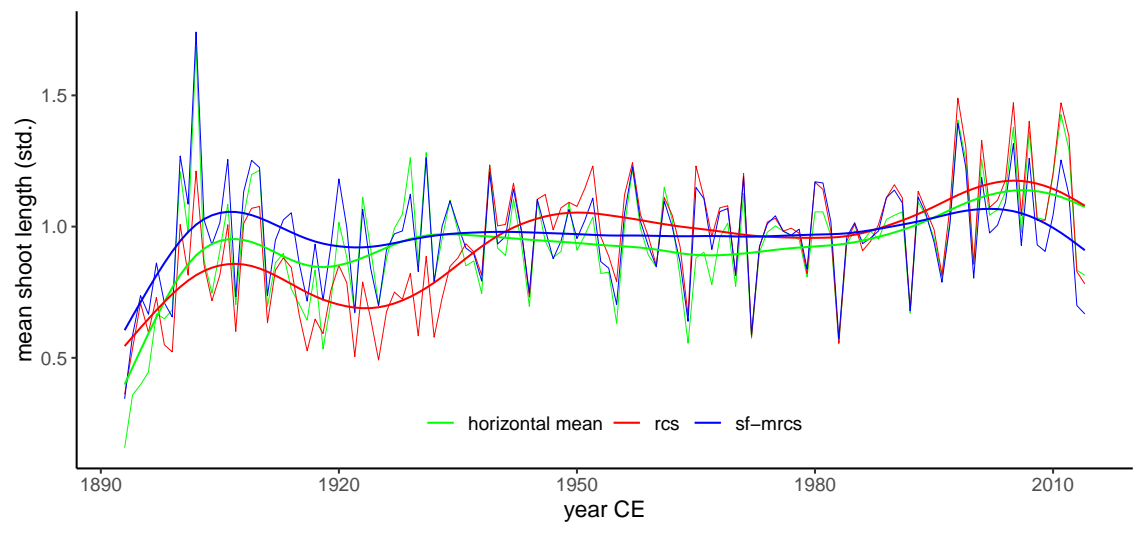


(a) 1893-2013

Model - early summer $\mathrm{T}$ - late summer $\mathrm{T}-$ prev. summer $\mathrm{P}-$ summer $\mathrm{T}$

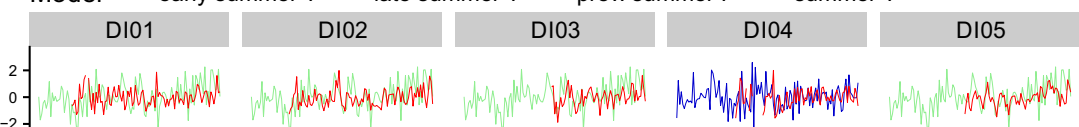
\begin{tabular}{|l|l|l|l|} 
DI06 DI07 & DI08 & DI09 & DI10
\end{tabular}

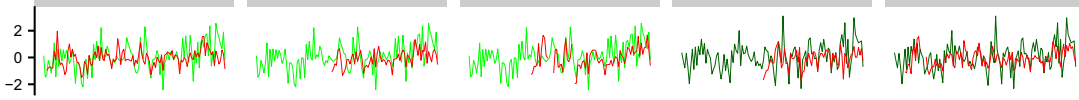
$\begin{array}{ccccc}\text { DI11 } & \text { DI12 } & \text { DI13 } & \text { DI14 } & \text { DI15 } \\ \text { DI16 } & \text { DI17 } & \text { DI18 } & \text { DI19 } & \text { DI20 }\end{array}$

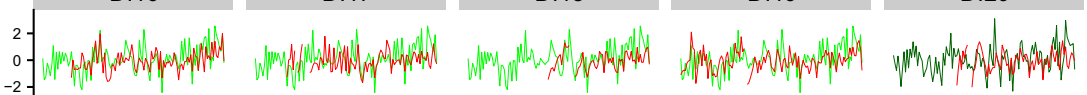

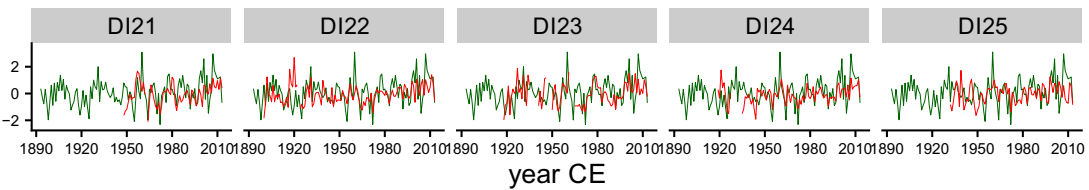

\section{(b) 1984-2013}

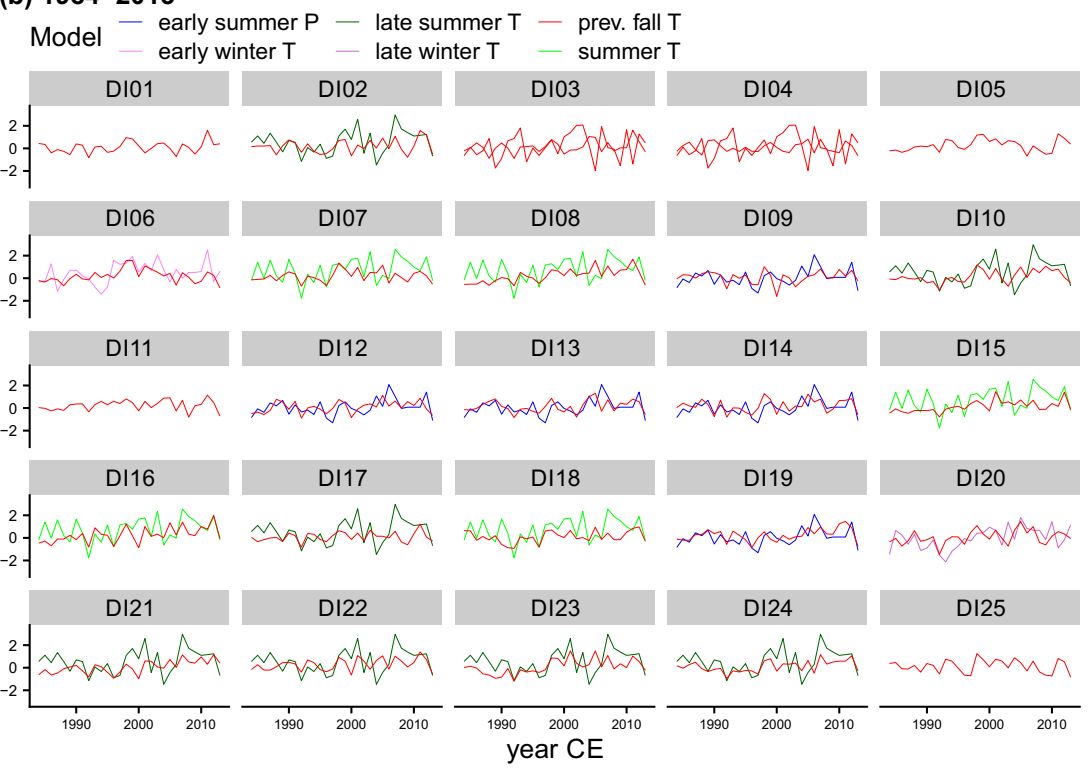




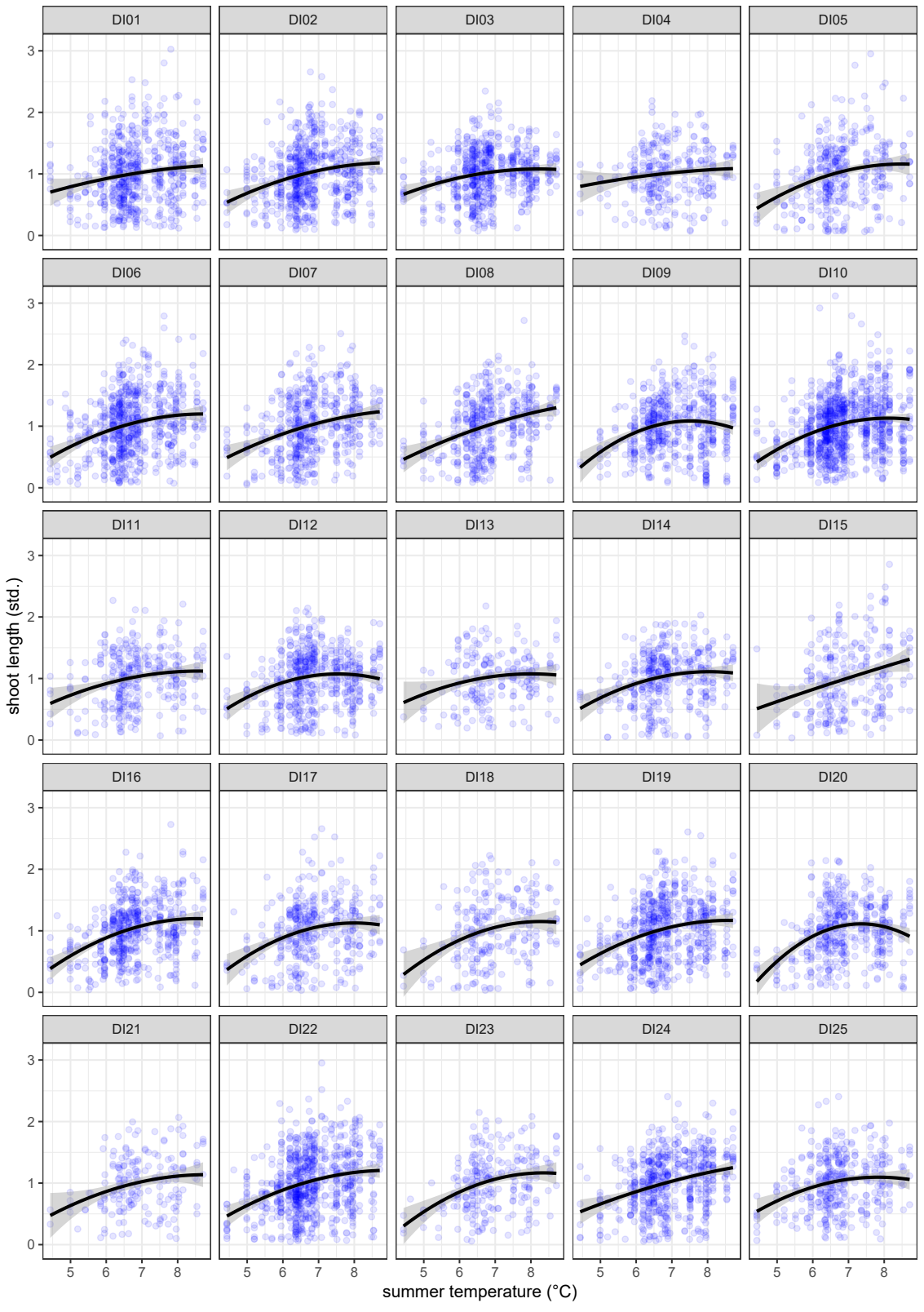


(a)
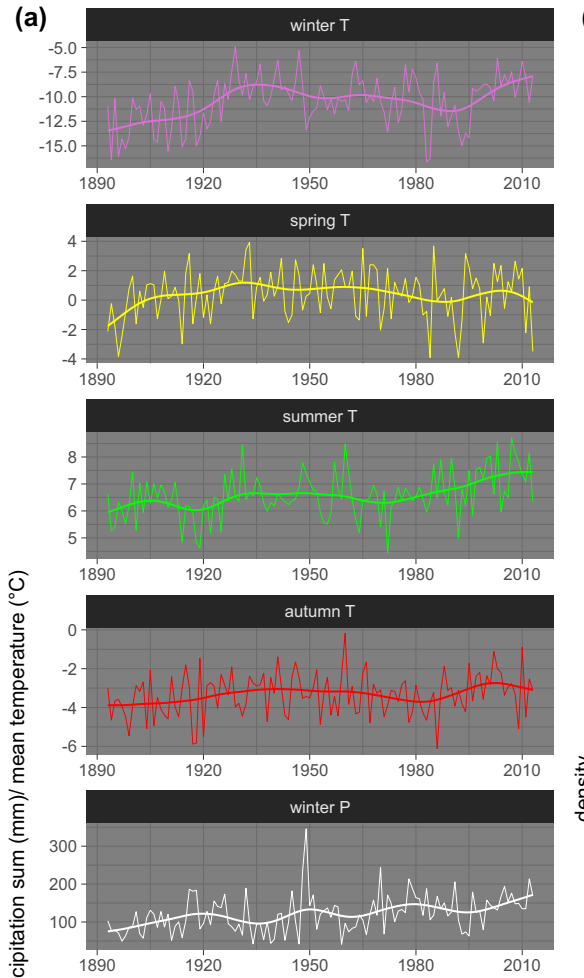

产
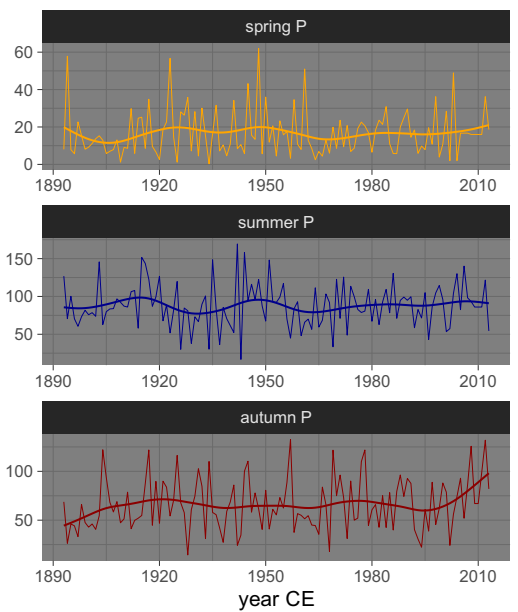

(b) winter T
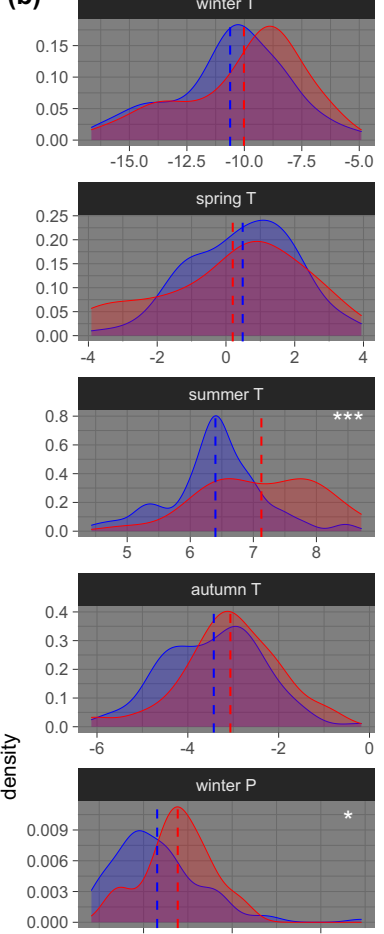

period

$1893-1983$
$1984-2013$

1984-2013
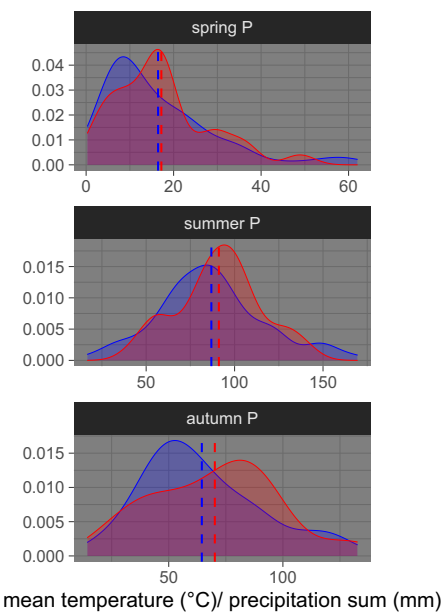

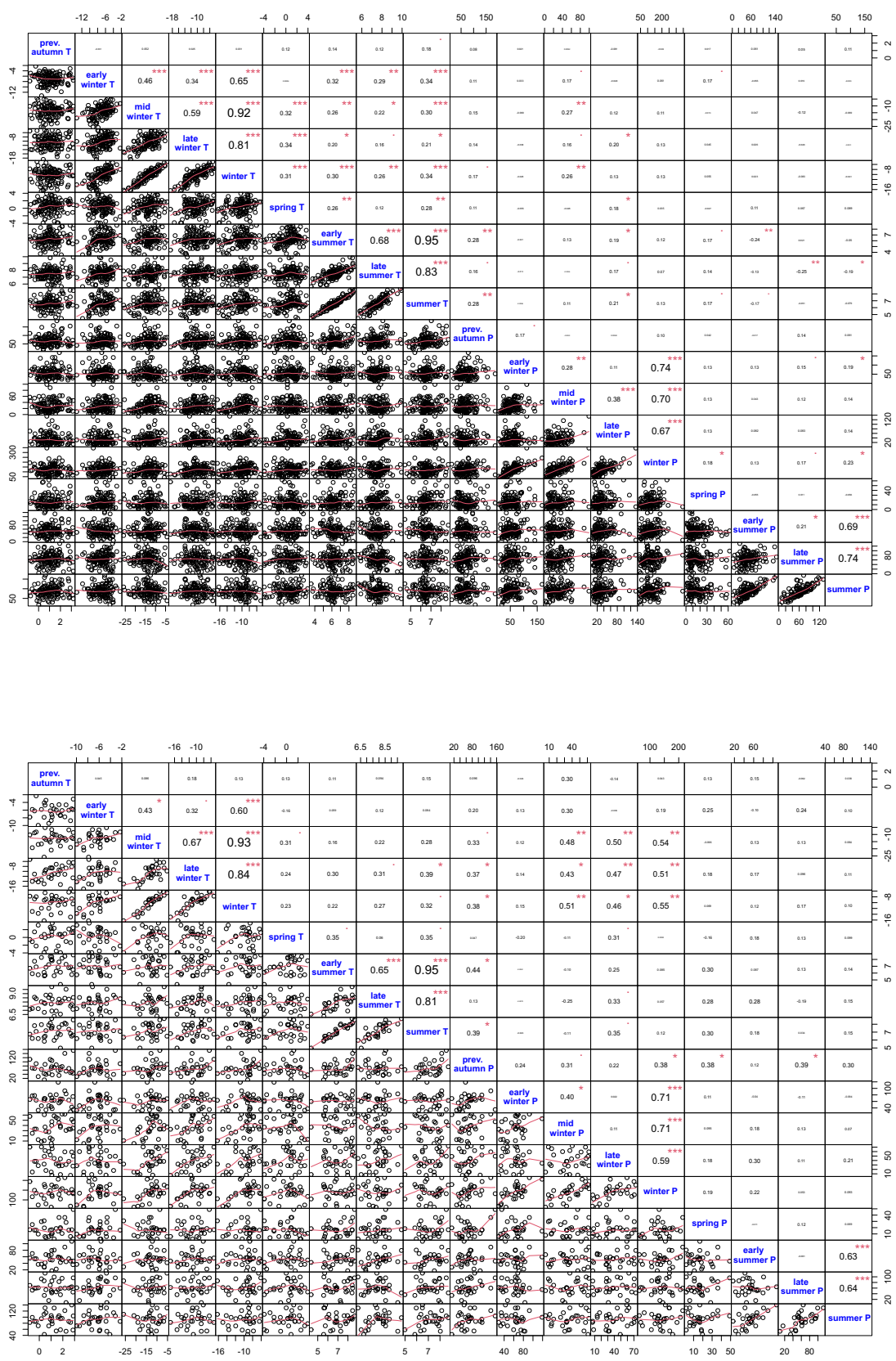

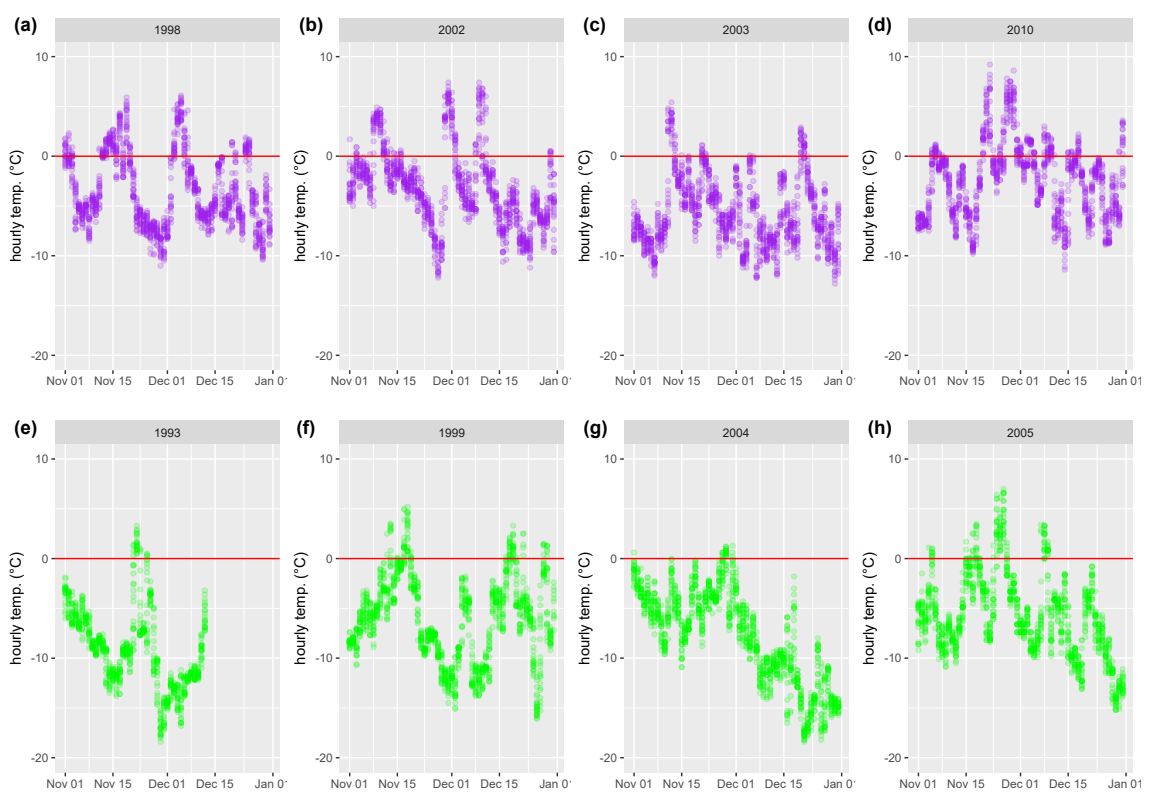